\title{
Safety, Pharmacokinetics, and Effects on Cognitive Function of Multiple Doses of GTS-2I in Healthy, Male Volunteers
}

\author{
Harumi Kitagawa', Toshiharu Takenouchi' ${ }^{2}$ Ryotaro Azuma ${ }^{3}$, Keith A Wesnes ${ }^{4}$, William G Kramer ${ }^{5}$, \\ Donald E Clody ${ }^{*}, 6$ and Angela L Burnett ${ }^{7}$ \\ 'Quintiles, Inc., Tokyo, Japan; ${ }^{2}$ Taiho Pharmaceutical Co. Ltd, Tokyo, Japan; ${ }^{3}$ Taiho Pharmaceutical Co. Ltd, Tokushima, Japan; ${ }^{4}$ Cognitive Drug \\ Research; Reading, UK; ${ }^{5}$ Kramer Consulting, LLC, North Potomac, MD, USA; ${ }^{6}$ Quintiles, Inc., Cranford, NJ, USA; ${ }^{7}$ Quintiles, Inc.; Rockville, MD, USA
}

\begin{abstract}
This study was designed to determine the safety, tolerability, pharmacokinetics and effects on cognitive function of GTS-2I in healthy, male volunteers. A total of 18 subjects were randomized to GTS-2I (25, 75 and I $50 \mathrm{mg}$ ) or placebo administered three times daily (first 4 days, once on Day 5) for three, 5-day sessions. GTS-2I was well tolerated up to doses of $450 \mathrm{mg} /$ day, with no clinically significant safety findings. $C_{\max }$ and the area under the plasma concentration of GTS-2I and the metabolite 4-OH-GTS-2I increased in a dose-related fashion; although considerable intersubject variability occurred, it decreased with continued dosing. GTS-2I showed statistically significant enhancement of three measures of cognitive function (attention, working memory, episodic secondary memory) compared to placebo. A relationship between exposure to GTS-2I and the magnitude of the cognitive response was apparent, with maximal effect approached for doses between 75 and $150 \mathrm{mg}$ three times a day. These data indicate that GTS-2I may represent a novel treatment for dementia. Neuropsychopharmacology (2003) 28, 542-55I. doi:I 0. I038/sj.npp. I 300028
\end{abstract}

Keywords: Alzheimer's disease; pharmacokinetics; cognition disorder

\section{INTRODUCTION}

Alzheimer's disease $(\mathrm{AD})$ is a progressive, degenerative, disabling disease and is the leading cause of dementia in the elderly (Mayeux and Schofield, 1994). Approximately 4 million individuals in the United States, and about $25 \%$ of Americans who are 85 years or older, are afflicted with $\mathrm{AD}$ or a related dementia (Strock, 1994). The cholinergic hypothesis of the impairment of memory and cognition observed in $\mathrm{AD}$ patients postulates that the impairment is due to a reduction in cholinergic function (Bartus et al, 1982). Evidence for this hypothesis includes findings that

The following parties contributed sufficiently to the research for, and writing of, this manuscript so as to take public responsibility for it, and affirm that this represents valid work whose results would be possible to reproduce with the same methods and conditions. Any financial or other affiliations with the sponsor are noted as follows: H Kitagawa, was employed by the Taiho Pharmaceutical Co. Ltd, during the time that the research discussed in this manuscript was conducted. KA Wesnes and WG Kramer were paid consultants for the Taiho Pharmaceutical Co. Ltd during the time that this research was conducted. DE Clody and $\mathrm{AL}$ Burnett worked under contract on behalf of the Taiho Pharmaceutical Co. Ltd at the time of this research.

* Correspondence: Dr DE Clody, Quintiles, Inc., 20 Commerce Drive Cranford, NJ 07016, USA, Tel: + I 908956 2256, Fax: + I 908709 |234, E-mail: Don.clody@quintiles.com

Received II September 200 I; revised I I June 2002; accepted 24 June 2002

Online publication: II July 2002 at http://www.acnp.org/citations/ Npp07| 102345 the degree of cognitive impairment in patients with $\mathrm{AD}$ is positively correlated with decreases in markers of cholinergic function measured in biopsied or post-mortem brains (Francis et al, 1985; Perry et al, 1978). In addition, the number of nicotinic acetylcholine receptors (nAChR) is reduced in the brains of AD patients (Schroder et al, 1991; Whitehouse et al, 1986). Consequently, it may be possible to improve the impairment in memory and cognitive function of AD patients and affect disease progression with nicotinic cholinergic agonists.

GTS-21 is a drug with a novel pharmacological profile, which has been shown to be an agonist at $\alpha-7$ nAChRs. The chemical name of GTS-21 is (E)-3-(2,4-dimethoxybenzylidene)-3,4,5,6-tetrahydro-2,3'-bipyridine dihydrochloride; the structures of GTS-21 and the pharmacologically active metabolite, 4-OH-GTS-21, are shown in Figure 1. GTS-21 is active in many animal models that are widely used to measure effects on memory and learning. GTS-21 was also effective in promoting cell survival in several in vitro and in vivo studies. Based on its preclinical profile, GTS- 21 is being developed for the treatment of both the cognitive dysfunction and neurodegeneration seen in patients with $\mathrm{AD}$. A total of 87 healthy, human subjects have been enrolled in four Phase I studies to evaluate GTS-21. In the first three studies, GTS-21 was found to be well tolerated at single doses up to $250 \mathrm{mg}$. This article summarizes the results of the fourth study - a randomized, placebocontrolled, multiple dose study of the safety, pharmacokinetics and cognitive effects of GTS-21 in healthy volunteers. 


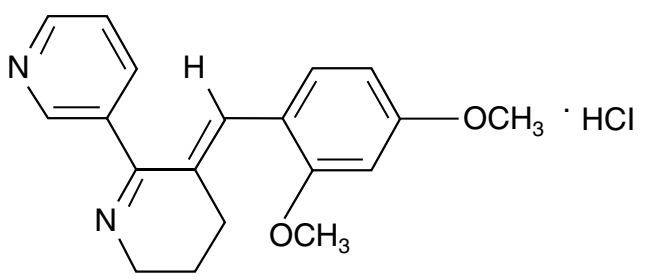

GTS-21

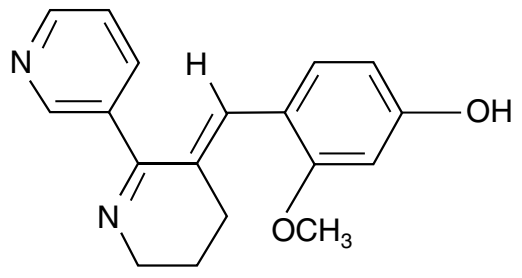

4-OH-GTS-21

Figure I Chemical structures of GTS-2I and 4-OH-GTS-2I.

\section{SUBJECTS AND METHODS}

\section{Subjects}

The study population comprised healthy, male volunteers aged 18-45 years; female volunteers were not included because the reproductive toxicity studies of GTS-21 had not been completed at the time of study initiation. Subjects were to be in good health as determined by a physical examination including vital signs, weight, clinical laboratory tests and electrocardiograms. Major exclusion criteria included the following: history of alcohol or drug dependency; positive result on urine drug screen; excessive caffeine use; and history of neurologic disorder, dementia, mental status change, severe head injury or serious psychiatric condition. The urine drug screen included the following: amphetamines, barbiturates, benzodiazepines, cocaine, morphine/opiate, methadone and tetrahydrocannabinol (THC). The study did not exclude subjects with a history of smoking, but smoking was not allowed during the study.

\section{Study Protocol}

This clinical trial was conducted at DDS Medicines Research Ltd in the UK in compliance with the Declaration of Helsinki and with regulatory requirements pertaining to informed consent and institutional review boards. The Ethics Review Board of the Tayside Committee on Medical Research, UK, approved the protocol prior to study initiation.

This was a single-center, randomized, placebo-controlled, double-blind, multiple dose study in a group of healthy, male volunteers. At baseline, the initial 16 eligible subjects who signed an informed consent were randomly assigned to either Group A (GTS-21, 12 subjects) or Group B (placebo, four subjects).

The treatment phase included three, 5-day treatment periods separated by 10 -day wash-out periods. During each of the three treatment sessions, subjects were restricted to the clinical site from the evening before the first dose until the morning after the last dose. Subject eligibility was verified by entry criteria and the urine drug screen at the beginning of each treatment period. The GTS-21 regimen was $25 \mathrm{mg}$ (treatment period 1), $75 \mathrm{mg}$ (treatment period 2) and $150 \mathrm{mg}$ (treatment period 3). Doses were administered three times a day (t.i.d.) $(0800,1400$, and $2000 \mathrm{~h})$ on Days $1-4$ and once $(0800 \mathrm{~h})$ on Day 5 of each treatment session. GTS-21 was supplied as coated tablets containing $25 \mathrm{mg}$ of the active ingredient GTS-21; placebo tablets were identical in appearance. All doses were administered immediately after a meal. All subjects were to return to the clinical site 57 days after their last dose for a follow-up visit to assess safety parameters.

Plasma was collected predose; 15, 30 and $45 \mathrm{~min}$; and 1, $1.25,1.5,2,3,4$ and $6 \mathrm{~h}$ postdose on Day 1 and Day 5 (08 00 dose). Additional samples were collected predose on Day 3 (08 00 dose) and Day 4 (14 00 dose), and at 8 and $12 \mathrm{~h}$ postdose on Day 5. Urine was collected predose and 0-2, 24 , and $4-6 \mathrm{~h}$ postdose on Day 1 (08 00 dose). Urine was also collected $0-2,2-4,4-6,6-8$ and 8-12 h postdose on Day 5. High-performance liquid chromatographic methods adapted from those described by Azuma were used to determine plasma (Azuma et al, 1996) and urine (internal report, Taiho Pharmaceutical Co.) concentrations of GTS-21 and 4-OH-GTS-21. Following solid-phase extraction, samples were chromatographed using a reverse-phase column with detection by visible absorbance at $405 \mathrm{~nm}$. The method was linear for plasma concentrations of GTS-21 and 4-OH-GTS-21 from 1 to $200 \mathrm{ng} / \mathrm{ml}$; the coefficient of variation for the parent was $7.3 \%$ at $5 \mathrm{ng} / \mathrm{ml}$ and $5.3 \%$ at $150 \mathrm{ng} / \mathrm{ml}$; and corresponding values for the metabolite were 14.7 and $9.5 \%$. For urine, the method was linear from 4 to $1000 \mathrm{ng} / \mathrm{mL}$ for both compounds, with coefficients of variation of 3.6 and $4.7 \%$ at GTS-21 concentrations of 10 and $750 \mathrm{ng} / \mathrm{ml}$, respectively, and 7.3 and $8.9 \%$ at those concentrations of the metabolite. Urine samples were subjected to enzymatic hydrolysis using $\beta$-glucuronidase followed by reanalysis for GTS-21 and 4-OH-GTS-21 to determine the extent of formation of glucuronide conjugates.

All subjects were evaluated for performance on a computerized test battery to measure the effects of treatment on cognitive functioning. Using computerized tests developed by Cognitive Drug Research Ltd (CDR) (Reading, UK), changes in attention, memory and reaction time from predose measurements were assessed during each session (Wesnes et al, 1988). Cognitive tests included the following: attention-related tests (simple reaction time, choice reaction time, digit vigilance), numeric and spatial working memory tests, secondary episodic recognition memory tests (word and picture recognition, immediate and delayed word recall) and visual tracking. In addition, an overnight face recognition test was administered and BondLader visual analog scales were used to assess subjective alertness, subjective contentment and subjective calmness (Bond and Lader, 1974). Two CDR training sessions were held prior to the first dosing period. Cognitive tests were performed on Day 1 ( $1 \mathrm{~h}$ predose) as well as on Days 2 and 4 of each treatment period ( $1 \mathrm{~h}$ predose and 1,2 , and $4 \mathrm{~h}$ after the $0800-h$ dose). 


\section{STATISTICAL/PHARMACOKINETIC ANALYSIS}

\section{Safety}

Descriptive statistical methods were used to summarize demographics, adverse events, ECG results and clinical laboratory tests.

\section{Pharmacokinetics}

Descriptive statistical methods were used to summarize plasma concentrations and amounts excreted in the urine of GTS-21 and 4-OH-GTS-21 and the resultant pharmacokinetic parameters. For GTS-21 and 4-OH-GTS-21, only those plasma or urine concentrations that were equal to or greater than the validated limit of the assay $(1 \mathrm{ng} / \mathrm{ml}$ for either compound in plasma and $10 \mathrm{ng} / \mathrm{ml}$ in urine) were used in the pharmacokinetic analyses. Actual blood sampling and urine collection times were used for all pharmacokinetic calculations. For graphical presentation of mean data, nominal times were used in the calculation of mean plasma concentrations and amounts excreted in the urine.

Pharmacokinetic parameters for GTS-21 and 4-OH-GTS21 were calculated using noncompartmental methods. $C_{\max }$ and $T_{\max }$ were taken directly from the data. The terminal elimination rate constant, $\lambda_{z}$, was calculated as the negative of the slope of the terminal log-linear portion of the plasma concentration time curve. The specific range of times was determined by graphical inspection of a semilogarithmic plot of concentration $v s$ time. Elimination half-life $\left(t_{1 / 2}\right)$ was calculated from $\lambda_{z}$ according to $t_{1 / 2}=0.693 / \lambda_{z}$. The area under the plasma concentration (AUC)-time curves to the last time point $\left(t_{\mathrm{f}}\right)$ with a concentration above the validated limit of quantitation $\left(C_{t_{\mathrm{f}}}\right)\left(\mathrm{AUC}_{t_{\mathrm{f}}}\right)($ Day 1$)$ and during the 6$\mathrm{h}$ dosing interval (Day 5) $\left(\mathrm{AUC}_{\tau}\right)$ were calculated using the linear trapezoidal method. $\mathrm{AUC}_{t_{\mathrm{f}}}$ on Day 1 was extrapolated to infinity $\left(\mathrm{AUC}_{\infty}\right)$ using $C_{t_{\mathrm{f}}}$ and $\lambda_{z}$, as shown below:

$$
\mathrm{AUC}_{\infty}=\mathrm{AUC}_{t_{\mathrm{f}}}+\frac{C_{t_{\mathrm{f}}}}{\lambda_{z}}
$$

On Day 5, if $t_{\mathrm{f}}$ occurred before the end of the dosing interval and a value was available for $\lambda_{z}$, AUC was extrapolated to the end of the dosing interval according to the following equation:

$$
\mathrm{AUC}_{\tau}=\frac{C_{t_{\mathrm{f}}}}{\lambda_{z}}\left(\mathrm{e}^{-\lambda_{z} \cdot t_{\mathrm{f}}}-\mathrm{e}^{-\lambda_{z} \cdot 6}\right)
$$

The fraction of the dose excreted in the urine through $24 \mathrm{~h}$ (Day 1) or $6 \mathrm{~h}$ (Day 5) (fe), calculated from the sum of the amounts in each collection interval, was expressed as a percent of the dose; amounts of the $4-\mathrm{OH}$ metabolite were corrected for the difference in molecular weight.

\section{Cognitive Function}

Both a primary analysis and a secondary (by dose period) analysis were performed on the cognitive assessment data. For the primary analysis, a two-way analysis of variance (ANOVA) was conducted. Five terms were fitted to the model: dosing condition, subjects nested within dosing condition, repeated testing, an interaction term between dosing condition and repeated testing, and an error term for this interaction. The two relevant statistical contrasts were
(1) a main effect of dosing condition, and (2) an interaction between dosing condition and repeated testing, reflecting an effect that depended on the time of assessment.

The secondary analysis was also performed to evaluate the treatment groups by dosing period. The difference from baseline data was averaged over each dosing period to derive a single score per measure for each subject. The data were subjected to a two-way ANOVA. Five terms were fitted to the model; these terms were the same as for the primary analysis except that the interaction term was between dosing condition and dosing periods. The two relevant statistical contrasts were (1) a main effect of dosing condition, and (2) an interaction between dosing condition and dosing period.

\section{Pharmacokinetic/Pharmacodynamic Modeling}

Potential relationships between the cognitive responses to GTS-21 and its pharmacokinetics were examined for immediate word recall accuracy, delayed word recall accuracy and digit vigilance. For each subject for each response, the area under the effect curve (AUEC) on Day 4 of dosing was calculated using the linear trapezoidal method, where effect was defined as the change from baseline. The difference in mean AUEC between GTS-21 and placebo at each dose was then plotted against the mean $\mathrm{AUC}_{\tau}$ on Day 5. Due to the short $t_{1 / 2}$ of GTS-21, concentrations on Day 5 were comparable to those on Day 1, and thus the $\mathrm{AUC}_{\tau}$ on Day 5 was considered to be representative of that on Day 4 when the cognitive responses were measured.

\section{RESULTS}

A total of 18 subjects, including two replacement subjects, were enrolled and received study drug (14 GTS-21, four placebo). Initially, 16 subjects were enrolled in the study (12 GTS-21, four placebo). Three subjects in the GTS-21 group discontinued early. One subject was discontinued in Session 3 at the sponsor's request because of elevated liver enzymes; one subject was chewing tablets instead of swallowing them and was discontinued in Session 1; and one subject left the study in Session 2 because he found employment. Two of these subjects were replaced; both were in the active treatment group. The demographics of the study population were similar between treatment groups. The mean age, height and weight was 33.2 years, $179.9 \mathrm{~cm}$ and $79.9 \mathrm{~kg}$ in the GTS-21 group, respectively, and 31.0 years, $175.0 \mathrm{~cm}$ and $72.2 \mathrm{~kg}$ in the placebo group, respectively. All subjects were Caucasians. Treatment compliance was controlled by the site, as the study drug was administered by the investigator or designee. Subject compliance with the study procedures was also assessed by the site staff.

\section{Safety}

GTS-21 was found to be well tolerated in healthy male volunteers up to a daily dose of $450 \mathrm{mg}$ ( $150 \mathrm{mg}$ t.i.d.). There were no clinically significant differences between treatment groups with respect to incidence of treatment-emergent adverse events. Table 1 shows the incidence of adverse events for all subjects. Although not considered to be 
Table I Incidence of Treatment-Emergent Adverse Events

\begin{tabular}{|c|c|c|c|c|c|}
\hline \multirow[b]{2}{*}{ Body system/AE } & \multicolumn{4}{|l|}{ GTS-2 I } & \multirow{2}{*}{$\begin{array}{l}\text { Placebo } \\
(N=4)\end{array}$} \\
\hline & $\begin{array}{l}25 \text { mg t.i.d. } \\
(N=12)\end{array}$ & $\begin{array}{l}75 \text { mg t.i.d. } \\
(N=12)\end{array}$ & $\begin{array}{l}150 \mathrm{mg} \text { t.i.d. } \\
(N=12)\end{array}$ & $\begin{array}{l}\text { Total } \\
(N=14)\end{array}$ & \\
\hline \multicolumn{6}{|l|}{ Skin and appendages } \\
\hline Dermatitis & 0 & 0 & I (8.3\%) & | (7.1\%) & 0 \\
\hline Eczema & | (8.3\%) & | (8.3\%) & 0 & $2(14.3 \%)$ & 0 \\
\hline Rash & 0 & 0 & 0 & 0 & I (25.0\%) \\
\hline \multicolumn{6}{|l|}{ Musculoskeletal } \\
\hline Arthralgia & I (8.3\%) & 0 & 0 & I (7.1\%) & 0 \\
\hline \multicolumn{6}{|c|}{ Central and peripheral nervous system } \\
\hline Dizziness & I (8.3\%) & I (8.3\%) & I (8.3\%) & I (7.1\%) & I (25.0\%) \\
\hline Headache & । (8.3\%) & $3(25.0 \%)$ & $3(25.0 \%)$ & $6(42.9 \%)$ & $2(50.0 \%)$ \\
\hline Paresthesia & 0 & 0 & 0 & 0 & I (25.0\%) \\
\hline \multicolumn{6}{|l|}{ Psychiatric } \\
\hline Agitation & 0 & 0 & | (8.3\%) & | (7.1\%) & 0 \\
\hline Euphoria & 0 & 0 & 0 & 0 & | (25.0\%) \\
\hline Insomnia & 0 & | (8.3\%) & 0 & | (7.1\%) & 0 \\
\hline Somnolence & 0 & | (8.3\%) & 0 & | (7.1\%) & I (25.0\%) \\
\hline \multicolumn{6}{|l|}{ Gastrointestinal } \\
\hline Abdominal pain & | (8.3\%) & 0 & 0 & | (7.l\%) & 0 \\
\hline Appetite increased & 0 & | (8.3\%) & 0 & I (7.1\%) & 0 \\
\hline Constipation & | (8.3\%) & 0 & 0 & I (7.1\%) & 0 \\
\hline Toothache & 0 & 0 & I (8.3\%) & I (7.1\%) & 0 \\
\hline \multicolumn{6}{|l|}{ Liver and Biliary } \\
\hline SGOT increased & 0 & | (8.3\%) & $3(25.0 \%)$ & $3(21.4 \%)$ & | (25.0\%) \\
\hline SGPT increased & 0 & $2(16.7 \%)$ & $3(25.0 \%)$ & $3(21.4 \%)$ & | (25.0\%) \\
\hline GGT increased & 0 & 0 & I (8.3\%) & I (7.1\%) & I (25.0\%) \\
\hline \multicolumn{6}{|l|}{ Cardiovascular } \\
\hline Hypotension postural & 0 & | (8.3\%) & 0 & I (7.1\%) & 0 \\
\hline \multicolumn{6}{|l|}{ Respiratory } \\
\hline Coughing & | (8.3\%) & 0 & | (8.3\%) & $2(14.3 \%)$ & | (25.0\%) \\
\hline Pharyngitis & $2(16.7 \%)$ & 0 & I (8.3\%) & $2(14.3 \%)$ & $2(50.0 \%)$ \\
\hline Rhinitis & 0 & $2(16.7 \%)$ & $3(25.0 \%)$ & $5(35.7 \%)$ & $4(100.0 \%)$ \\
\hline \multicolumn{6}{|l|}{ Platelet, bleeding, clotting } \\
\hline Purpura & | (8.3\%) & | (8.3\%) & 0 & $2(14.3 \%)$ & 0 \\
\hline \multicolumn{6}{|l|}{ Body as a whole } \\
\hline Back pain & $2(14.3 \%)$ & 0 & 0 & $2(14.3 \%)$ & | (25.0\%) \\
\hline Fatigue & 0 & | (8.3\%) & 0 & I (7.1\%) & 0 \\
\hline Edema peripheral & 0 & 0 & 0 & 0 & I (25.0\%) \\
\hline Pain & 0 & 0 & 0 & 0 & 0 \\
\hline \multicolumn{6}{|l|}{ Application site } \\
\hline Injection site pain & 0 & 0 & I (8.3\%) & I (7.l\%) & 0 \\
\hline \multicolumn{6}{|l|}{ Secondary terms } \\
\hline Inflicted injury & 0 & 0 & I (8.3\%) & I (7.1\%) & 0 \\
\hline Abrasion not specified & 0 & | (8.3\%) & | (8.3\%) & $2(14.3 \%)$ & 0 \\
\hline
\end{tabular}

Note: Multiple occurrences of the same adverse event in the same subject were counted once per dose group.

This table presents adverse event data for all patients who received study drug (GTS-2I or placebo).

clinically significant, adverse events relating to hepatic function in four subjects were notable and are discussed below. There were no clinically significant, treatmentemergent changes reported with respect to ECG findings or physical examinations. No clinically significant, treatment-emergent trends were noted with respect to vital signs, although one subject was reported to have asympto- matic postural hypotension at the $75 \mathrm{mg}$ t.i.d. dose level. This subject did not experience dizziness, nor did the adverse event meet the following criteria for orthostatic hypotension: decrease of $20 \mathrm{mmHg}$ in systolic blood pressure accompanied by an increase of $20 \mathrm{bpm}$ in pulse.

Adverse events relating to abnormal hepatic function occurred in three (21.4\%) subjects in the GTS-21 group and 
Table 2 Summary of Adverse Events Related to Liver Function

\begin{tabular}{|c|c|c|c|c|c|c|}
\hline Subject & Treatment & Session/Day & Value (U/L) & Out of range & AE & Relationship \\
\hline \multirow[t]{2}{*}{1204} & \multirow[t]{2}{*}{ GTS-2। 150 mg t.i.d. } & \multirow[t]{2}{*}{ S3/Day 6} & SGOT 39 & I.I × ULN & SGOT incr & Probably \\
\hline & & & SGPT 68 & $1.7 \times$ ULN & SGPT incr & Probably \\
\hline \multirow[t]{16}{*}{1205} & GTS-2 I 75 mg t.i.d. & s2/Day 6 & SGPT 50 & $1.3 \times$ ULN & SGPT incr & Possibly \\
\hline & \multirow[t]{15}{*}{ GTS-2। $150 \mathrm{mg}$ t.i.d. } & \multirow[t]{3}{*}{ S3/Day 3} & SGOT 107 & $3.0 \times$ ULN & SGOT incr & Possibly \\
\hline & & & SGPT 114 & $2.9 \times \cup L N$ & SGPT incr & Possibly \\
\hline & & & GGT 89 & $1.9 \times \cup L N$ & GGT incr & Possibly \\
\hline & & \multirow[t]{6}{*}{ S3/Day 4} & SGOT 122 & $3.4 \times$ ULN & & \\
\hline & & & SGOT 97 & $2.7 \times \cup L N$ & & \\
\hline & & & SGPT I 58 & $4.1 \times$ ULN & & \\
\hline & & & SGPT 165 & $4.2 \times \cup \operatorname{UL}$ & & \\
\hline & & & GGT 125 & $2.7 \times \cup L N$ & & \\
\hline & & & GGT 137 & $3.0 \times \cup L N$ & & \\
\hline & & \multirow[t]{3}{*}{ S3/Day 5} & SGOT 72 & $2.0 \times \cup L N$ & & \\
\hline & & & SGPT I49 & $3.8 \times \cup L N$ & & \\
\hline & & & GGT I40 & $3.0 \times U L \mathrm{LN}$ & & \\
\hline & & \multirow[t]{3}{*}{ S3/Day 6} & SGOT 3.8 & $1.1 \times$ ULN & & \\
\hline & & & SGPT IOI & $2.6 \times U L N$ & & \\
\hline & & & GGT 112 & $2.4 \times \cup L N$ & & \\
\hline \multirow[t]{4}{*}{1213} & \multirow[t]{2}{*}{ GTS-2I 75 mg t.i.d. } & \multirow[t]{2}{*}{ S2/Day I } & SGOT 47 & $1.3 \times$ ULN & SGOT incr & Remotely \\
\hline & & & SGPT 70 & $1.8 \times U L N$ & SGPT incr & Remotely \\
\hline & \multirow[t]{2}{*}{ GTS-2I $150 \mathrm{mg}$ t.i.d. } & \multirow[t]{2}{*}{ S3/Day 6} & SGOT 40 & $1.1 \times$ ULN & SGOT incr & Possibly \\
\hline & & & SGPT 59 & $1.5 \times$ ULN & SGPT incr & Possibly \\
\hline \multirow[t]{4}{*}{1209} & \multirow[t]{2}{*}{ Placebo } & SI/Day 6 & SGPT 62 & $1.6 \times$ ULN & SGPT incr & Possibly \\
\hline & & Washout & GGT 5I & I.I × ULN & GGT incr & Possibly \\
\hline & Placebo & S2/Day 6 & SGOT 98 & $2.7 \times U L N$ & SGOT iner & Possibly \\
\hline & Placebo & S3/Day 6 & SGPT 52 & $1.3 \times U L N$ & SGPT incr & Probably \\
\hline
\end{tabular}

Note: All liver enzyme values returned to clinically acceptable limits by the 7-day follow-up visit.

Normal ranges were as follows: SGOT 10-36 U/L, SGPT 8-39 U/L, GGT 2-46 U/L.

one $(25.0 \%)$ subject in the placebo group (Table 2$)$. Of these four subjects, one GTS- 21 subject and one placebo subject showed liver enzyme values $>2$ times the upper limit of the normal range (ULN). The maximum SGOT, SGPT and GGT values for the GTS- 21 subject were $3.4 \times$ ULN, $4.2 \times$ ULN and $3.0 \times \mathrm{ULN}$, respectively. This subject was withdrawn from the study at the sponsor's request. The maximum SGOT, SGPT and GGT values for the placebo subject were $2.7 \times \mathrm{ULN}, 1.3 \times \mathrm{ULN}$ and $1.1 \times \mathrm{ULN}$, respectively. Only one of these four subjects was discontinued early, as stated above; the other three subjects with liver enzyme elevations all completed the study. None of the subjects who experienced liver enzyme elevations showed evidence of hepatic dysfunction and all liver enzyme values had returned to clinically acceptable limits by the 7-day follow-up visit.

\section{Pharmacokinetics}

The mean plasma GTS-21 and 4-OH-GTS-21 concentrationtime profiles on Days 1 and 5 after administration of GTS21 daily for 5 days under fed conditions are shown in Figure 2. The mean $\pm S D$ and range of the pharmacokinetic parameters derived from the individual subject data are listed in Table 3 for GTS-21 and Table 4 for the metabolite.

Plasma GTS-21 concentrations reached their peak at 1$1.4 \mathrm{~h}$ after the first dose and 1-1.2 $\mathrm{h}$ after 5 days of dosing, consistent with values for $T_{\max }$ observed in previous studies (internal reports, Taiho Pharmaceutical Co.) (Table 3).

The pharmacokinetics of the metabolite, 4-OH-GTS-21, paralleled those of the parent. Concentrations reached their peak at $0.9-1.5 \mathrm{~h}$ after the first dose and $1.1-1.3 \mathrm{~h}$ after 5 days of dosing, again consistent with values for $T_{\max }$ observed in previous studies (internal reports, Taiho Pharmaceutical Co.) (Table 4).

Urinary excretion of unchanged GTS-21 and 4-OH-GTS21 accounted for less than $0.5 \%$ of the dose (Tables 3 and 4 ). Following enzymatic hydrolysis, there was evidence for small amounts of a conjugated form of GTS-21 (Table 5). Conjugated 4-OH-GTS-21, however, accounted for $6-7 \%$ of the dose on Day 1 and $10-12 \%$ on Day 5.

\section{Cognitive Function}

The data in this study indicate a clear effect of GTS-21 over placebo on a range of cognitive functions. Table 6 summarizes the results of the ANOVA analysis of the cognitive data. For the primary analysis, statistically significant effects of GTS-21 were observed for at least one measure of all three attention-related tasks (simple reaction time, choice reaction time and digit vigilance), two secondary episodic recognition memory tasks (word recognition and picture recognition), and for the numeric working memory task. Additionally, both the visual tracking tasks and the immediate word recall task exhibited statistically significant improvements in performance following dosing with GTS-21. Tasks for which there were no effects on performance as indicated by the primary analysis were the spatial working memory task, the delayed word recall task, overnight face recognition task, and the BondLader self-ratings of mood and alertness. The secondary analysis confirmed the main effects of GTS- 21 seen in the primary analysis (Figures 3-5) and, in addition, showed significant improvement for immediate and delayed word recall (Figures 6 and 7) as well as one measure of spatial working memory. 

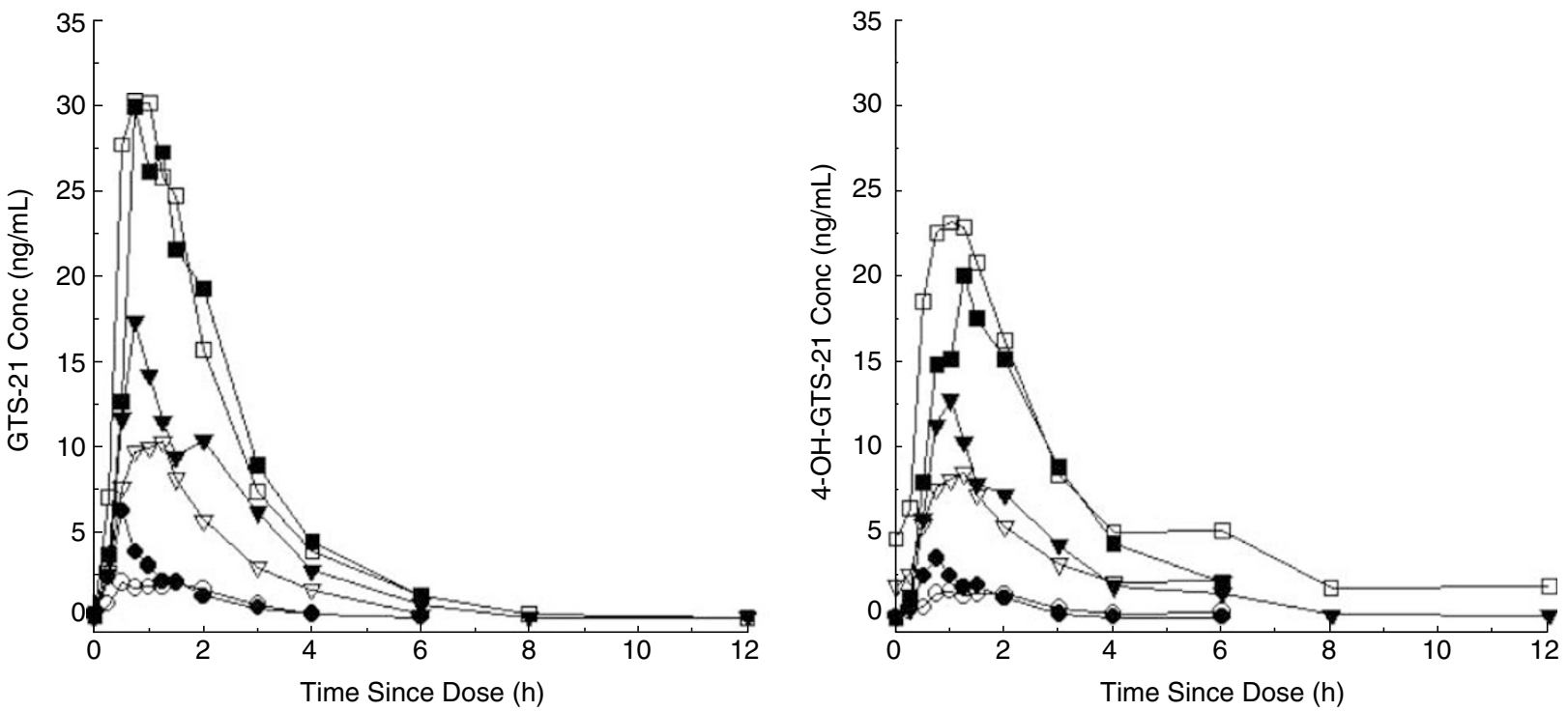

$\begin{array}{ll}\bullet 25 \mathrm{mg} \text { Day } 1 & \rightarrow 75 \mathrm{mg} \text { Day } 1 \rightarrow 150 \mathrm{mg} \text { Day } 1 \\ -25 \mathrm{mg} \text { Day } 5 \rightarrow 75 \mathrm{mg} \text { Day } 5 \rightarrow 150 \mathrm{mg} \text { Day } 5\end{array}$

Figure 2 Mean plasma concentrations of GTS-2I (left panel) and 4-OH-GTS-2I (right panel) after administration of 25, 75, and I50 mg t.i.d. for 4 days and q.d. for I day.

Table 3 Mean \pm SD (Range) Pharmacokinetic Parameters for GTS-2I after Oral Administration of 25, 75, and I $50 \mathrm{mg}$ of GTS-2 I Daily for 5 Days

\begin{tabular}{|c|c|c|c|}
\hline Parameter & $25 \mathrm{mg}$ & $75 \mathrm{mg}$ & $150 \mathrm{mg}$ \\
\hline \multicolumn{4}{|l|}{ Day 1} \\
\hline$C_{\max }(\mathrm{ng} / \mathrm{ml})$ & $\begin{array}{c}8.58 \pm 11.2 \\
(1.71 \rightarrow 36.3)\end{array}$ & $\begin{array}{c}20.0 \pm 20.5 \\
(3.49 \rightarrow 68.5)\end{array}$ & $\begin{array}{r}40.1 \pm 48.1 \\
(8.57 \rightarrow \mid 47)\end{array}$ \\
\hline$T_{\max }(h)$ & $\begin{array}{l}1.00 \pm 0.78 \\
(0.25 \rightarrow 3.0)\end{array}$ & $\begin{array}{l}1.17 \pm 0.69 \\
(0.5 \rightarrow 3.0)\end{array}$ & $\begin{array}{l}|.42 \pm 0.7| \\
(0.27 \rightarrow 3.0)\end{array}$ \\
\hline $\mathrm{ACU}_{t_{f}}(\mathrm{~h} \mathrm{ng} / \mathrm{ml})$ & $\begin{array}{c}8.11 \pm 13.2 \\
(0.99 \rightarrow 46.1)\end{array}$ & $\begin{array}{c}37.9 \pm 52.9 \\
(6.14 \rightarrow 195)\end{array}$ & $\begin{array}{c}66.0 \pm 65.3 \\
(15.5 \rightarrow 236)\end{array}$ \\
\hline$A \cup C_{\infty}(h n g / m l)$ & $\begin{array}{c}\mid 3.0 \pm 16.1 \\
(2.09 \rightarrow 47.9)\end{array}$ & $\begin{array}{r}44.4 \pm 59.6 \\
(7.07 \rightarrow 203)\end{array}$ & $\begin{array}{l}77.4 \pm 69.0 \\
(|8.2 \rightarrow 24|)\end{array}$ \\
\hline$t_{1 / 2}(h)$ & $\begin{array}{r}0.76 \pm 0.38 \\
(0.35 \rightarrow 1.47)\end{array}$ & $\begin{array}{c}0.93 \pm 0.32 \\
(0.53 \rightarrow 1.55)\end{array}$ & $\begin{array}{r}0.93 \pm 0.19 \\
(0.52 \rightarrow 1.16)\end{array}$ \\
\hline fe (\% dose) & $\begin{array}{r}0.012 \pm 0.008 \\
(0.006 \rightarrow 0.027)\end{array}$ & $\begin{array}{r}0.012 \pm 0.005 \\
(0.005 \rightarrow 0.023)\end{array}$ & $\begin{array}{r}0.017 \pm 0.007 \\
(0.007 \rightarrow 0.034)\end{array}$ \\
\hline \multicolumn{4}{|l|}{ Day 5} \\
\hline$C_{\max }(\mathrm{ng} / \mathrm{ml})$ & $\begin{array}{c}3.49 \pm 0.99 \\
(1.76 \rightarrow 4.85)\end{array}$ & $\begin{array}{c}12.8 \pm 8.23 \\
(5.18 \rightarrow 33.0)\end{array}$ & $\begin{array}{r}47.8 \pm 28.4 \\
(21.1 \rightarrow \mid 17)\end{array}$ \\
\hline$T_{\max }(h)$ & $\begin{array}{l}1.19 \pm 0.60 \\
(0.5 \rightarrow 2.0)\end{array}$ & $\begin{array}{l}1.09 \pm 0.28 \\
(0.75 \rightarrow 1.5)\end{array}$ & $\begin{array}{l}1.02 \pm 0.38 \\
(0.5 \rightarrow 1.5)\end{array}$ \\
\hline $\begin{array}{l}\mathrm{ACU}_{t_{\varphi}} \text { or } \\
\mathrm{AUC}_{\tau}(\mathrm{h} \mathrm{ng} / \mathrm{ml}) \\
\text { fe }(\% \text { dose) }\end{array}$ & $\begin{array}{c}4.57 \pm 2.62 \\
(2.70 \rightarrow 12.3) \\
0.009 \pm 0.008 \\
(0.0 \rightarrow 0.022)\end{array}$ & $\begin{array}{c}32.7 \pm 16.4 \\
(21.1 \rightarrow 44.4) \\
0.017 \pm 0.005 \\
(0.008 \rightarrow 0.025)\end{array}$ & $\begin{array}{c}85.1 \pm 32.9 \\
(46.7 \rightarrow 138) \\
0.021 \pm 0.009 \\
(0.0 \rightarrow 0.036)\end{array}$ \\
\hline
\end{tabular}

Note: $C_{\max }$ - maximum plasma concentration, $T_{\max }$ - time to $C_{\max }$, AUC area under the curve, $t_{1 / 2}$ - elimination half-life, fe - percent of dose excreted in the urine.

\section{Pharmacokinetic/Pharmacodynamic Relationship}

The relationship between the cognitive responses to GTS-21 (as measured by immediate word recall accuracy, delayed word recall accuracy and digit vigilance task) and drug exposure is illustrated in Figure 8. For the three tests
Table 4 Mean \pm SD (Range) Pharmacokinetic Parameters for 4-OH-GTS-2I after Oral Administration of 25, 75, and $150 \mathrm{mg}$ of GTS-2I Daily for 5 Days

\begin{tabular}{|c|c|c|c|}
\hline Parameter & $25 \mathrm{mg}$ & $75 \mathrm{mg}$ & $150 \mathrm{mg}$ \\
\hline \multicolumn{4}{|l|}{ Day 1} \\
\hline$C_{\max }(\mathrm{ng} / \mathrm{ml})$ & $\begin{array}{r}5.75 \pm 4.63 \\
(1.49 \rightarrow 16.3)\end{array}$ & $\begin{array}{r}14.2 \pm 14.8 \\
(2.52 \rightarrow 54.4)\end{array}$ & $\begin{array}{r}27.4 \pm 25.8 \\
(7.22 \rightarrow 86.3)\end{array}$ \\
\hline$T_{\max }(h)$ & $\begin{array}{l}0.86 \pm 0.33 \\
(0.5 \rightarrow 1.5)\end{array}$ & $\begin{array}{l}1.25 \pm 0.65 \\
(0.75 \rightarrow 3.0)\end{array}$ & $\begin{array}{l}1.48 \pm 0.64 \\
(0.5 \rightarrow 3.0)\end{array}$ \\
\hline $\mathrm{ACU}_{t_{f}}(\mathrm{hng} / \mathrm{ml})$ & $\begin{array}{c}5.59 \pm 5.75 \\
(1.38 \rightarrow 19.7)\end{array}$ & $\begin{array}{l}27.3 \pm 25.1 \\
(2.54 \rightarrow 82.8)\end{array}$ & $\begin{array}{r}50.0 \pm 35.3 \\
(15.8 \rightarrow 124)\end{array}$ \\
\hline $\mathrm{AUC}_{\infty}(\mathrm{h} n g / \mathrm{ml})$ & $\begin{array}{c}9.39 \pm 6.81 \\
(3.45 \rightarrow 22.8)\end{array}$ & $\begin{array}{r}32.4 \pm 29.2 \\
(4.19 \rightarrow 85.6)\end{array}$ & $\begin{array}{r}55.7 \pm 38.0 \\
(20.9 \rightarrow 126)\end{array}$ \\
\hline$t_{1 / 2}(\mathrm{~h})$ & $\begin{array}{r}0.81 \pm 0.30 \\
(0.59 \rightarrow 1.25)\end{array}$ & $\begin{array}{c}1.18 \pm 0.41 \\
(0.73 \rightarrow 1.68)\end{array}$ & $\begin{array}{c}1.15 \pm 0.37 \\
(0.74 \rightarrow 1.86)\end{array}$ \\
\hline fe (\% dose) & $\begin{array}{c}0.031 \pm 0.022 \\
(0.005 \rightarrow 0.075)\end{array}$ & $\begin{array}{r}0.030 \pm 0.018 \\
(0.009 \rightarrow 0.061)\end{array}$ & $\begin{array}{c}0.047 \pm 0.037 \\
(0.016 \rightarrow 0.15)\end{array}$ \\
\hline \multicolumn{4}{|l|}{ Day 5} \\
\hline$C_{\max }(\mathrm{ng} / \mathrm{ml})$ & $\begin{array}{c}2.71 \pm 1.12 \\
(1.73 \rightarrow 4.61)\end{array}$ & $\begin{array}{r}9.87 \pm 5.19 \\
(3.81 \rightarrow 19.3)\end{array}$ & $\begin{array}{c}32.9 \pm 18.3 \\
(12.8 \rightarrow 80.8)\end{array}$ \\
\hline$T_{\max }(\mathrm{h})$ & $\begin{array}{l}1.30 \pm 0.58 \\
(0.75 \rightarrow 2.0)\end{array}$ & $\begin{array}{l}|.23 \pm 0.5| \\
(0.5 \rightarrow 2.0)\end{array}$ & $\begin{array}{l}1.11 \pm 0.48 \\
(0.5 \rightarrow 2)\end{array}$ \\
\hline $\mathrm{AUC}_{\tau}(\mathrm{hng} / \mathrm{ml})$ & $\begin{array}{c}7.49 \pm 4.73 \\
(0.77 \rightarrow \mid 1.9)\end{array}$ & $\begin{array}{c}26.2 \pm 5.72 \\
(18.2 \rightarrow 37.7)\end{array}$ & $\begin{array}{r}71.3 \pm 24.9 \\
(37.2 \rightarrow 136)\end{array}$ \\
\hline fe (\% dose) & $\begin{array}{l}0.062 \pm 0.038 \\
(0.008 \rightarrow 0.14)\end{array}$ & $\begin{array}{c}0.074 \pm 0.042 \\
(0.035 \rightarrow 0.18)\end{array}$ & $\begin{array}{c}0.11 \pm 0.085 \\
(0.013 \rightarrow 0.30)\end{array}$ \\
\hline
\end{tabular}

examined, there appeared to be a relationship between exposure to GTS-21 and the magnitude of the response.

\section{DISCUSSION}

This study was conducted to evaluate the safety, pharmacokinetics and cognitive effects of GTS-21 after multiple doses of 25,75 and $150 \mathrm{mg}$ per day for 5 days in healthy male volunteers. 
Table 5 Mean $( \pm \mathrm{SD})$ Urinary Excretion ${ }^{\mathrm{a}}$ of GTS-2I, 4-OH-GTS-2I, and Conjugates after Administration of 25,75 , and $150 \mathrm{mg}$ of GTS- 21 tid $\times 5$

\begin{tabular}{|c|c|c|c|c|c|}
\hline \multirow[b]{2}{*}{ Day } & \multirow[b]{2}{*}{ Dose } & \multicolumn{2}{|l|}{ GTS-2 I } & \multicolumn{2}{|c|}{ 4-OH-GTS-2I } \\
\hline & & Free & Conjugate & Free & Conjugate \\
\hline I & $\begin{array}{r}25 \\
75 \\
150\end{array}$ & $\begin{array}{l}0.011 \pm 0.008 \\
0.012 \pm 0.005 \\
0.017 \pm 0.007\end{array}$ & $\begin{array}{l}0.047 \pm 0.030 \\
0.058 \pm 0.037 \\
0.053 \pm 0.032\end{array}$ & $\begin{array}{l}0.029 \pm 0.024 \\
0.031 \pm 0.018 \\
0.049 \pm 0.039\end{array}$ & $\begin{array}{l}6.97 \pm 2.77 \\
7.29 \pm 3.20 \\
5.78 \pm 1.62\end{array}$ \\
\hline 5 & $\begin{array}{r}25 \\
75 \\
150\end{array}$ & $\begin{array}{l}0.010 \pm 0.008 \\
0.016 \pm 0.005 \\
0.019 \pm 0.009\end{array}$ & $\begin{array}{l}0.114 \pm 0.056 \\
0.128 \pm 0.056 \\
0.132 \pm 0.062\end{array}$ & $\begin{array}{l}0.042 \pm 0.026 \\
0.054 \pm 0.027 \\
0.083 \pm 0.066\end{array}$ & $\begin{array}{l}10.2 \pm 3.03 \\
\mid 2.1 \pm 3.81 \\
\mid 1.0 \pm 4.31\end{array}$ \\
\hline
\end{tabular}

${ }^{\mathrm{a}}$ Based on urine collected from 0 to $6 \mathrm{~h}$ on each study day.

Table 6 Summary of Cognitive Function Testing (P-Values from ANOVA Analysis)

\begin{tabular}{|c|c|c|c|c|c|}
\hline & \multicolumn{2}{|c|}{ Primary analysis } & \multicolumn{3}{|c|}{ Secondary analysis (by dosing period) } \\
\hline & $\begin{array}{l}\text { Main effect } \\
\text { of GTS-2 I } \\
(N=\mid 6)\end{array}$ & $\begin{array}{l}\text { Interaction with } \\
\text { repeated testing } \\
(N=16)\end{array}$ & $\begin{array}{l}\text { Treatment } \\
\text { period I } \\
(N=16)\end{array}$ & $\begin{array}{l}\text { Treatment } \\
\text { period } 2 \\
(N=16)\end{array}$ & $\begin{array}{l}\text { Treatment } \\
\text { period } 3 \\
(N=16)\end{array}$ \\
\hline \multicolumn{6}{|l|}{ Attention-related tasks } \\
\hline Simple reaction time & 0.0237 & 0.0443 & 0.0059 & 0.0042 & 0.0019 \\
\hline Choice reaction time & NS & 0.0276 & 0.0003 & NS & 0.0703 \\
\hline \multicolumn{6}{|l|}{ Digit vigilance } \\
\hline Correct detections & 0.0130 & 0.0026 & 0.0419 & 0.0052 & 0.0001 \\
\hline Speed of detections & NS & 0.002 & 0.0087 & NS & NS \\
\hline \multicolumn{6}{|l|}{ Working memory tasks } \\
\hline \multicolumn{6}{|c|}{ Numeric working memory } \\
\hline Sensitivity & NS & 0.0001 & NS & NS & 0.0023 \\
\hline Speed & NS & NS & 0.0446 & 0.0524 & 0.0992 \\
\hline \multicolumn{6}{|l|}{ Spatial working memory } \\
\hline Sensitivity & NS & NS & 0.0420 & NS & NS \\
\hline Speed & NS & NS & 0.0053 & 0.0491 & 0.0529 \\
\hline \multicolumn{6}{|c|}{$\begin{array}{l}\text { Secondary episodic recognition } \\
\text { memory tasks }\end{array}$} \\
\hline \multicolumn{6}{|c|}{ Word recognition } \\
\hline Sensitivity & 0.0293 & 0.0048 & 0.0004 & 0.0007 & 0.0245 \\
\hline Speed & NS & NS & 0.0969 & 0.0557 & NS \\
\hline \multicolumn{6}{|l|}{ Picture recognition } \\
\hline Sensitivity & NS & 0.0358 & NS & 0.0515 & 0.0155 \\
\hline Speed & NS & NS & NS & 0.0325 & NS \\
\hline Immediate word recall & 0.1039 & NS & 0.0020 & 0.0002 & 0.0001 \\
\hline Delayed word recall & NS & NS & 0.0005 & 0.0001 & 0.0005 \\
\hline \multicolumn{6}{|l|}{ Other tasks (coordination) } \\
\hline Visual tracking & NS & 0.0293 & NS & NS & 0.0428 \\
\hline
\end{tabular}

Note: Trends toward statistical significance are shown in italics.

NS - Not statistically significant.

GTS-21 was well tolerated up to a daily dose of $450 \mathrm{mg}$ (150 mg t.i.d). There were no clinically significant, treatmentemergent changes reported with respect to ECG findings, physical examinations and vital signs; one subject experienced asymptomatic postural hypotension at the $75 \mathrm{mg}$ t.i.d. dose level. There were no clinically significant differences between treatment groups with respect to the incidence of adverse events. However, due to the elevated liver enzymes in four subjects, the potential for hepatotoxicity was examined carefully. The literature suggests that laboratory results in healthy subjects should be interpreted cautiously in Phase I studies, as LFT elevations may be a result of nondrug factors such as diet or environment, and do occur in placebo subjects as well as those treated with study drug (Purkins et al, 1997, Rosenzweig et al, 1999, Merz et al, 1997). In this study, none of the adverse events relating to hepatic function were determined to be clinically significant, and none of the subjects exhibited signs of hepatic dysfunction. This finding was consistent with preclinical data. The no observable effect level of GTS-21 in a 4-week rat study was determined to be $150 \mathrm{mg} / \mathrm{kg} / \mathrm{day}$; significant increases in liver weight and hepatocellular hypertrophy were only seen at $450 \mathrm{mg} / \mathrm{kg} /$ day. Nevertheless, future studies of GTS-21 will track LFT abnormalities carefully.

The pharmacokinetics of GTS-21 and 4-OH-GTS-21 appeared to be linear over the range of doses studied, as 


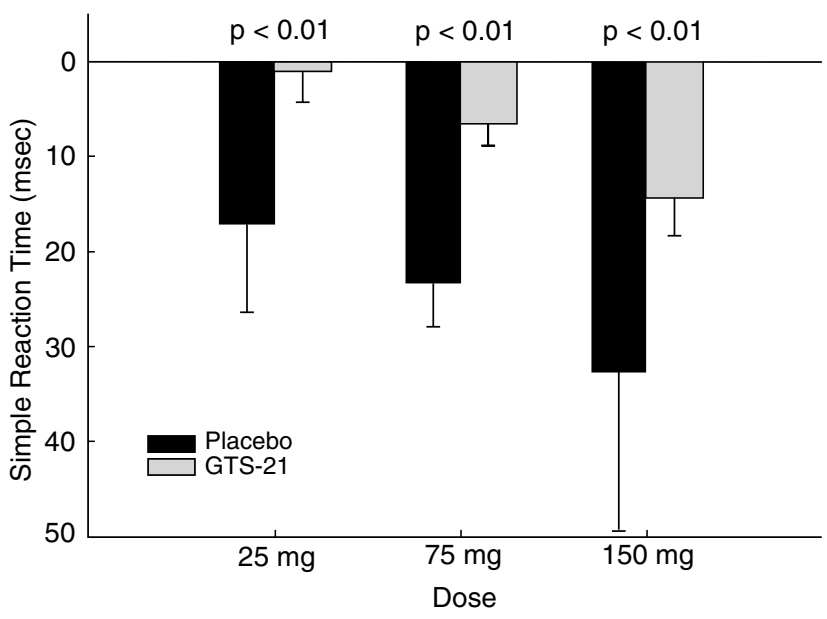

Figure 3 Effect of GTS-2I on simple reaction time as a function of dose and treatment group.

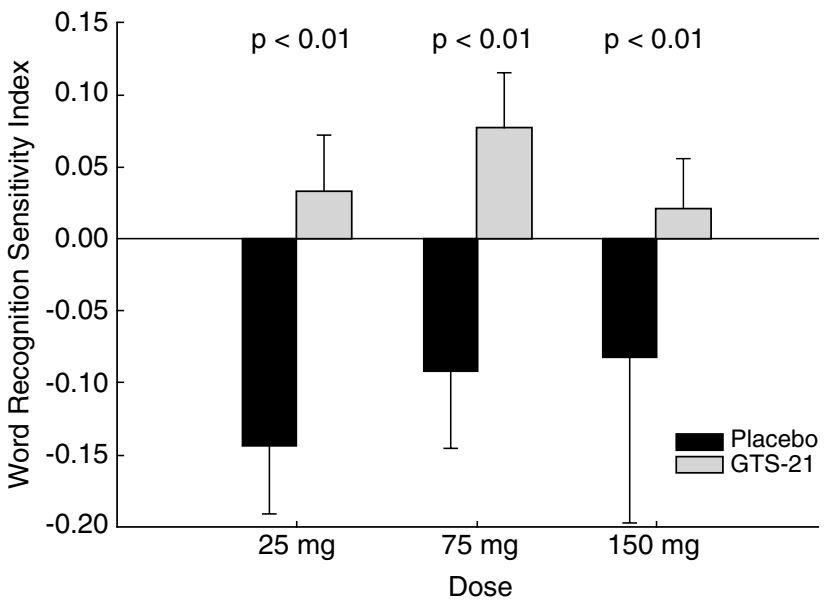

Figure 4 Effect of GTS-2I on word recognition sensitivity as a function of dose and treatment group.

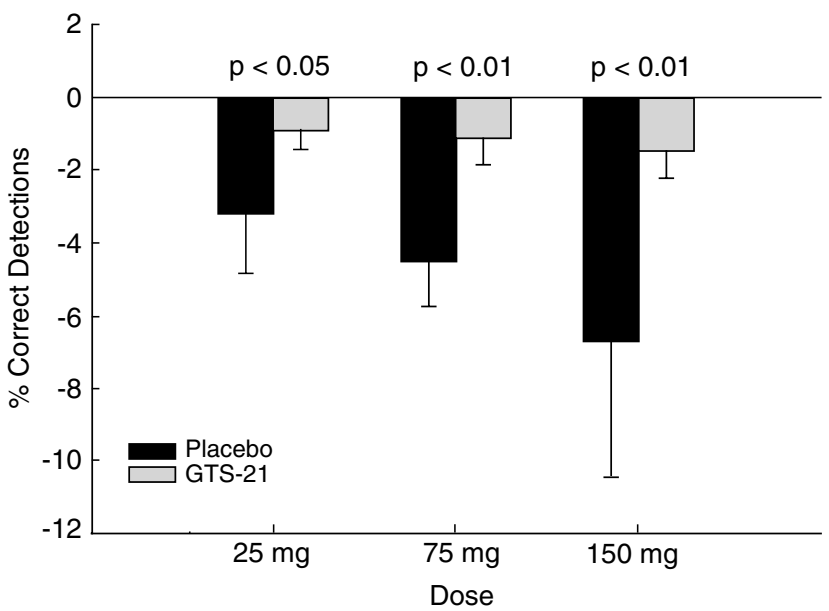

Figure 5 Effect of GTS-2I on digit vigilance as a function of dose and treatment group.

evidenced by increases in $C_{\max }, \mathrm{AUC}_{\infty}$ and/or $\mathrm{AUC}_{\tau}$ that were proportional to dose, within the limits of the observed variability. Elimination half-life was also indepen-

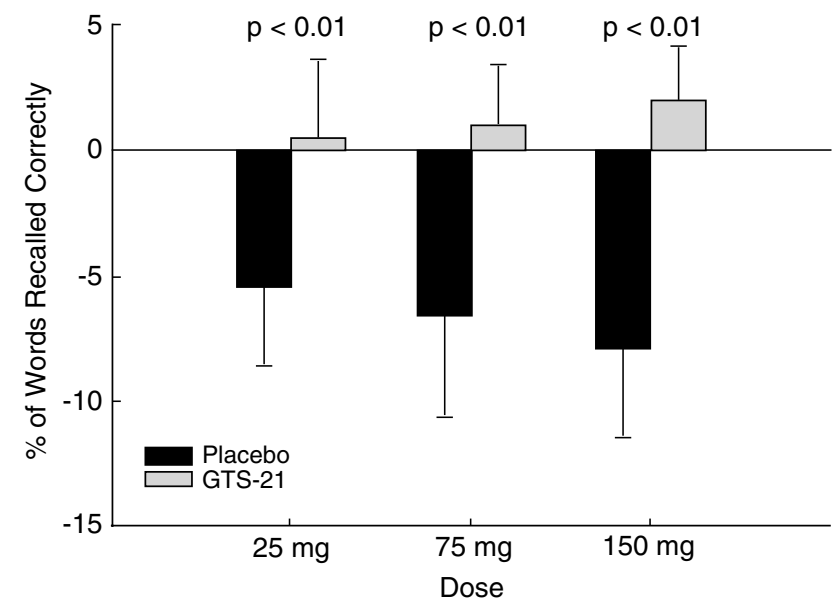

Figure 6 Effect of GTS-2I on immediate word recall accuracy as a function of dose and treatment group.

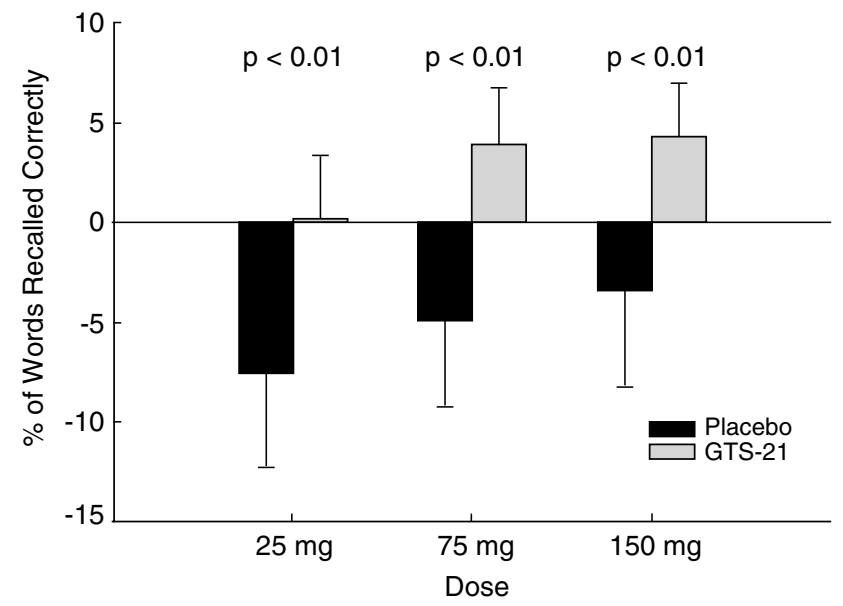

Figure 7 Effect of GTS-2I on delayed word recall accuracy as a function of dose and treatment group.

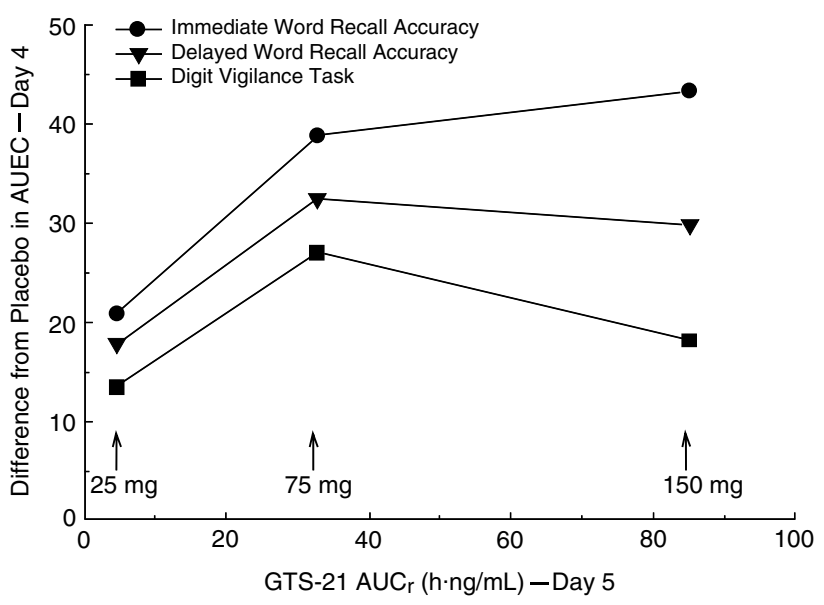

Figure 8 Relationship between the effects of GTS-2I on immediate and delayed word recall accuracy and digit vigilance (AUEC) and drug exposure (AUC).

dent of dose, providing further evidence of linearity. As demonstrated in a previous study (internal report, Taiho Pharmaceutical Co.), the wide range in pharmacoki- 
netic parameters of GTS-21 and 4-OH-GTS-21 is due to between-subject variability, with essentially no intrasubject contribution. Consistent with these observations, there was considerable intersubject variability in $C_{\max }$ and AUC $_{\infty}$ of GTS-21 (Table 3). However, the ranges at steady state (Day 5) were 2.1 to 6.4 -fold, considerably less than the 13 to 29-fold observed after the first dose, indicating that the intersubject variability in pharmacokinetics may decrease with continued dosing. The ranges in $C_{\max }$ and AUC at steady state (Day 5) for the metabolite were 2.1 to 15 -fold, somewhat less than the 6 to 22 -fold observed after the first dose. This is consistent with the parent and provides further evidence that the intersubject variability in pharmacokinetics may decrease with multiple dosing. Consistent with a $t_{1 / 2}$ of approximately $1 \mathrm{~h}$ and a dosing interval of at least $6 \mathrm{~h}$, there was essentially no accumulation of either the parent or metabolite after 5 days of dosing (Figure 2).

The CDR computerized assessment system has been designed to identify changes in the quality of several major aspects of human cognitive function, including attention and memory. It is currently the most widely used system of its type in worldwide clinical research. The core tests on the system were initially developed to identify the cognitive effects of drugs acting on brain cholinergic systems, primarily nicotine and scopolamine (Wesnes and Warburton, 1984). The various tests in the system are highly sensitive to a variety of compounds that can enhance cognitive function, particularly those that influence the cholinergic system (van Harten et al, 1996; Parrott et al, 1996).

The data in this study strongly supported the hypothesis that GTS-21 has a favorable effect on cognitive function and are very encouraging for the future development of GTS-21 as a cognition enhancer. Firstly, the effects are consistent with the pharmacological actions of the compound; for example, nicotine has long been known to enhance vigilance (Wesnes and Warburton, 1984) and has also been shown to produce similar effects on the vigilance task used in this study (Parrott et al, 1996). Secondly, the effects detected also go beyond the simple effects of nicotine and physostigmine. For example, there is no evidence that nicotine has favorable effects on episodic memory, in contrast to the clear effects of GTS-21 on this function. In addition, although nicotine has been shown to affect attention, and physostigmine affects both attention and episodic memory, the results indicate that GTS-21 shows positive effects on both these aspects of cognitive function as well as working memory.

As illustrated in Figure 8, there appears to be a relationship between the exposure to GTS-21, as measured by $\mathrm{AUC}_{\tau}$, and its cognitive effects, based on the difference from placebo in AUEC. Response increased between 25 and $75 \mathrm{mg}$, and appeared to plateau between 75 and $150 \mathrm{mg}$. The 24-h exposure on Day 4 is essentially the same as that on Day 1, for which minimal or no cognitive effects were seen. The effect may thus be a function of both the magnitude and duration of exposure. A relationship identical to that shown in Figure 8 was also observed for the active metabolite and the sum of parent and metabolite (not shown), and the observed effect may be related to both compounds.
In conclusion, GTS-21 was well tolerated up to doses of $450 \mathrm{mg} /$ day (150 mg t.i.d.) and shows improvements in cognitive behavior in normal subjects. The pharmacokinetics appear to be linear over the range of dose studies and the variability, primarily intersubject, decrease with continued dosing. The data provide important evidence that GTS-21 has the potential to improve human cognitive function. The range of the effects is important, clear benefits being seen to three major cognitive functions (attention, working memory, episodic secondary memory). In addition, there appears to be a relationship between the duration and magnitude of exposure to GTS-21 and/or 4-OH-GTS-21 and the magnitude of effect, with doses between 75 and $150 \mathrm{mg}$ t.i.d. approaching maximal effect. GTS-21 may represent a novel treatment for dementia, and should be investigated further for its potential therapeutic effects in a variety of conditions in which cognitive function is compromised, not least of all Alzheimer's disease.

\section{ACKNOWLEDGEMENT}

This study was funded by Taiho Pharmaceutical Co. Ltd, Japan.

\section{REFERENCES}

Azuma R, Minami Y, Satoh T (1996). Simultaneous determination of GTS-21 and its metabolite in rat plasma by high-performance liquid chromatography using solid-phase extraction. J Chromatogr B Biomed Appl 686: 229-234.

Bartus RT, Dean RL, Beer B, Lippa AS (1982). The cholinergic hypothesis of geriatric memory dysfunction. Science 217: 408414.

Bond A, Lader M (1974). The use of analogue scales in rating subjective feelings. Br J Med Psychol 47: 211-218.

Francis PT, Palmer AM, Sims NR, Bowen DM, Davison AN, Esiri MM et al (1985). Neurochemical studies of early-onset alzheimer's disease. Possible influence on treatment. $N$ Engl $J$ Med 313: 7-11.

Mayeux R, Schofield PW (1994). Alzheimer's disease. In: Hazzard WR, Bierman EL, Blass JP, Ettinger WH, Halter JB (eds). Principles of Geriatric Medicine and Gerontology, 3rd edn. McGraw Hill: New York, 1035-1050.

Merz M, Seiberling M, Höxter G, Hölting M, Wortha HP (1997). Elevation of liver enzymes in multiple dose trials during placebo treatment: are they predictable? J Clin Pharmacol 37: 791-798.

Parrott A, Garnham N, Wesnes K, Pincock P (1996). Cigarette smoking and abstinence: comparative effects upon cognitive task performance and mood state over 24 hours. Hum Psychopharmacol 11: 391-400.

Perry EK, Tomlinson BE, Blessed G, Bergmann K, Gibson PH, Perry RH (1978). Correlation of cholinergic abnormalities with senile plaques and mental test scores in senile dementia. BMJ 2: 1457-1459.

Purkins L, Eve MD, Love ER, Smith C, Cowen C (1997). The effect of diet on selected liver function tests. Eur J Clin Pharmacol 52: A115.

Rosenzweig P, Miget N, Brohier S (1999). Transaminase elevation on placebo during Phase I trials: prevalence and significance. $\mathrm{Br}$ J Clin Pharmacol 48: 19-23.

Schroder H, Giacobini E, Struble RG, Zilles K, Maelicke A (1991). Nicotinic cholinoceptive neurons of the frontal 
cortex are reduced in Alzheimer's disease. Neurobiol Aging 12: $259-262$.

Strock M (1994). Alzheimer's Disease. Information Resources and Inquiries Branch, Office of Scientific Information, National Institute of Mental Health (NIMH). NIH Publication No. 943676. NIH: Washington, DC.

van Harten J, Olff M, Wesnes K, Strobel W (1996). Flesinoxan improves cognition in the elderly. Eur Neuropsychopharmacol 6(Suppl. 3): 186.
Wesnes K, Simpson PM, Kidd AG (1988). An investigation of the range of cognitive impairments induced by scopolamine $0.6 \mathrm{mg}$. Hum Psychopharmacol 3: 27-41.

Wesnes K, Warburton DM (1984). Effects of scopolamine and nicotine on human rapid information processing performance. Psychopharmacology 82: 147-150.

Whitehouse PJ, Martino AM, Antuono PG, Lowenstein PR, Coyle JT, Price DL et al (1986). Nicotinic acetylcholine binding sites in Alzheimer's disease. Brain Res 371: 146-151. 